Dolor abdominal e infección por el virus varicela zoster tras trasplante de médula ósea

\title{
Abdominal pain and infection by the varicella-zoster virus following bone marrow transplant
}

J. Gutiérrez ${ }^{1}$, J.M. Zozaya ${ }^{2}$, M. Iñarrairaegui ${ }^{2}$, J.J. Vila², A. Arín ${ }^{2}$, F. Borda ${ }^{2}$

\section{RESUMEN}

La infección por el virus varicela zoster (VVZ) es una importante causa de morbi-mortalidad en pacientes receptores de trasplante de médula ósea (TMO), tanto autólogo como alogénico. La infección generalmente se produce en el primer año post-trasplante y, en su forma diseminada, puede manifestarse por dolor abdominal que traduce la afectación visceral, dolor que puede preceder en días a la aparición de las lesiones cutáneas características dificultando el diagnóstico. Se describe el caso clínico de una paciente que, 10 meses después de un TMO, presenta una infección por VVZ manifestada por dolor abdominal por afectación hepática, con un intervalo entre el inicio del dolor y la aparición de lesiones cutáneas de 2 días. Se discute el diagnóstico y tratamiento de estos pacientes.

Palabras clave. Virus varicela zoster (VVZ). Trasplante de médula ósea (TMO). Afectación visceral.

\begin{abstract}
Infection by the varicella-zoster virus (VZV) is an important cause of morbidity and mortality in patients who have received a bone marrow transplantation (BMT), both autologue and alogenic. Infection is generally produced in the first post-transplant year and, in its disseminated form, it can show itself through abdominal pain that translates the visceral affectation, pain that can precede the appearance of the characteristic cutaneous lesions by days, making diagnosis difficult. The clinical case described belongs to a patient who, 10 months after a bone marrow transplant, showed an infection by varicella-zoster virus, manifested through abdominal pain due to hepatic affectation, with an interval of 2 days between the start of pain and the appearance of cutaneous lesions. The diagnosis and treatment of these patients is discussed.
\end{abstract}

Key words. Varicella-zoster virus (VZV). Bone marrow transplantation (BMT). Visceral affectation.
1. Servicio de Medicina Interna. Hospital de Navarra

2. Servicio de Aparato Digestivo. Hospital de Navarra

Aceptado para su publicación el 5 de noviembre de 2002 .

\author{
Correspondencia \\ Jorge Gutiérrez Dubois \\ Servicio de Medicina Interna \\ Hospital de Navarra \\ Irunlarrea, 3 \\ 31008 Pamplona \\ Tfno. 948422135 \\ E-mail: Miriano2001@yahoo.es
}




\section{INTRODUCCIÓN}

La infección por el VVZ es una importante causa de morbi-mortalidad en pacientes inmunocomprometidos. El riesgo de padecerla es particularmente elevado en los pacientes receptores de un TMO, ya sea autólogo o alogénico ${ }^{1}$. En estos pacientes, cuando la infección por el VVZ se presenta en forma diseminada puede manifestarse como un dolor abdominal inespecífico acompañado de náuseas y vómitos, con o sin la aparición simultánea de las lesiones cutáneas características, lo cual puede retrasar el diagnóstico y el tratamiento adecuado suponiendo un aumento de la morbi-mortalidad.

\section{CASO CLÍNICO}

Presentamos el caso de una paciente de 56 años, con antecedentes de linfoma no Hodgkin (LNH) de alto grado tratado con poliquimioterapia y autoTMO 10 meses antes, que ingresa por presentar un cuadro de 24 horas de evolución de dolor abdominal epigástrico, de carácter intenso pero de instauración progresiva, que irradia en cinturón y se acompaña de náuseas y vómitos biliosos. No refiere fiebre ni otra clínica acompañante. A la exploración la paciente se encontraba afectada por el dolor, siendo el estado nutricional, la hidratación y la coloración cutáneomucosa normales. La auscultación cardio-pulmonar era normal y el abdomen era blando y depresible, pero intensamente doloroso a la palpación en epigastrio y ambos hipocondrios, sin que existiesen signos de irritación peritoneal y sin objetivarse masas, visceromegalias, ni ruidos abdominales anormales. En la analítica se observaba: $\mathrm{Hb}, 11,7$ $\mathrm{g} / \mathrm{dl}$; Hto, 33,1\%; leucocitos, 2,4 x $10 / \mathrm{L}$ (N $84 \%$, L 30\%; M 14\%; B 0,6\%); plaquetas $85 \times 10 / \mathrm{L}$; VSG: $35 \mathrm{~mm} / \mathrm{h}$. El ionograma, la amilasa, lipasa, albúmina y la función renal eran normales. La función hepática, salvo una ligera elevación de la gamma-glutil-transferasa (GGT: $39 \mathrm{U} / \mathrm{L}$; VN: 6$28 \mathrm{U} / \mathrm{L}$ ), era también normal. Las radiografías simples de abdomen y de tórax, y el ECG no mostraban alteraciones. El estudio ecográfico fue normal, excepto por el hallazgo de riñones en herradura. En la tomografía computarizada abdominal se observó una leve hepatoesplenomegalia con lesiones hipodensas en hígado, en relación con quistes hepáticos simples ya conocidos, y una lesión hipodensa mal definida en bazo que podía estar en relación con su proceso linfomatoso, junto con la malformación renal ya descrita en la ecografía y dilatación de asas intestinales con niveles hidroaéreos. Se practicó una gastroscopia en la que se encontró una hernia de hiato no complicada. Pese a la normalidad de los resultados, la paciente continuaba con intenso dolor abdominal que requirió la utilización de analgésicos opiáceos. Transcurridos dos días de ingreso, la paciente presentó una erupción vesiculosa y pruriginosa (Fig. 1) en tórax, que posteriormente se extendió a abdomen, espalda, región facial y extremidades, acompañándose con posterioridad de fiebre (hasta $38,4^{\circ}$ ). Coincidiendo con la erupción cutánea, se observó un aumento de las enzimas hepáticas hasta valores de fosfatasa alcalina (FA) de $1354 \mathrm{U} / \mathrm{L}$ (VN 98-279 U/L), aspartatoamino-transferasa (AST) de $96 \mathrm{U} / \mathrm{L}$ (VN 0-18 $\mathrm{U} / \mathrm{L}$ ), alanino-amino-transferasa (ALT) de 129 U/L (VN 0-22 U/L) y GGT de 335 U/L, siendo los valores de amilasa y lipasa normales. Ante la sospecha diagnóstica de infección por VVZ se inició tratamiento con Aciclovir iv, desapareciendo el dolor y de la fiebre en el plazo de 48 horas. El tratamiento se mantuvo durante 10 días en los que se observó progresiva disminución de los valores de las enzimas hepáticas. Un mes después del alta la paciente se encontraba

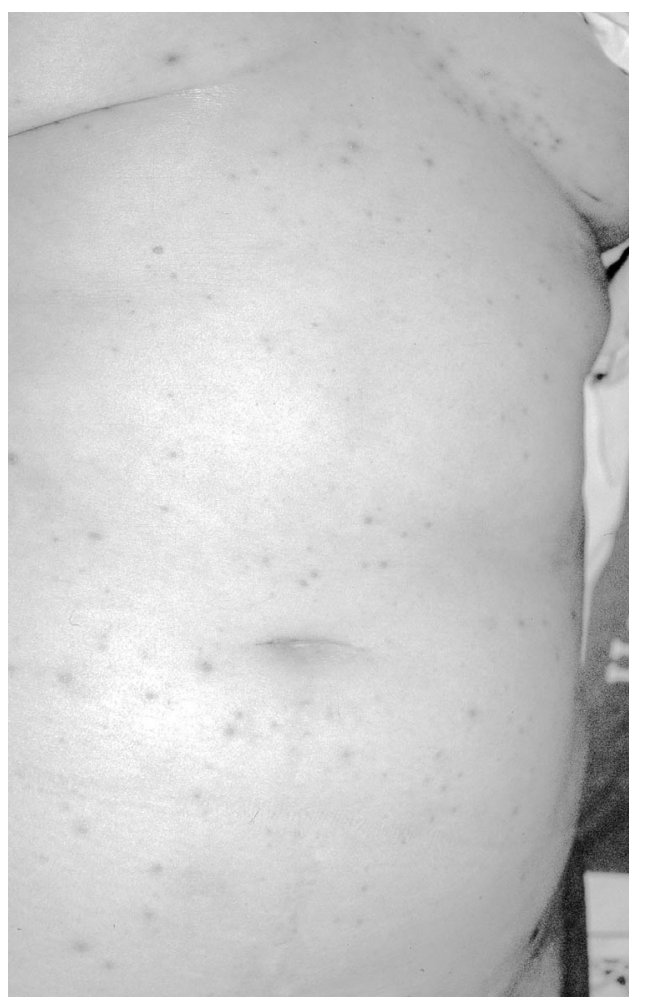

Figura 1. Lesiones dérmicas en tórax y abdomen, típicas de varicela. 
totalmente restablecida y las pruebas de laboratorio se habían normalizado.

\section{DISCUSIÓN}

La infección por el VVZ es una importante causa de morbi-mortalidad en pacientes inmunodeprimidos. La prevalencia de dicha infección en pacientes con TMO varía del $17-50 \%$ apareciendo, generalmente, dentro del primer año tras el transplante, tal y como ocurrió en el caso que nos ocupa en el que la infección se produjo diez meses después del trasplante ${ }^{1-3}$.

La presentación más frecuente de la infección por el VVZ suele ser la afectación de un dermatoma por el herpes zoster. Puede presentarse también como herpes zoster diseminado, como varicela cutánea o como diseminación visceral de la varice$\mathrm{la}^{1}$. Generalmente se produce por reactivación del virus, que queda acantonado en los ganglios de las raíces dorsales, asociándose varios factores de riesgo para el desarrollo de la infección, como la enfermedad de base (mayor en LH y LNH), la edad (mayores de 10 años), la aparición conjunta de enfermedad injerto contra el huésped $(\mathrm{EICH})$, la radioterapia previa al TMO, la administración de fármacos inmunosupresores y de globulina antitimocítica, y la seropositividad para $\mathrm{VVZ}^{14}$.

En la mayor parte de los afectados, la infección se limita a la aparición de un zóster localizado, en cuyo caso la formación de vesículas continúa más de una semana y las costras suelen aparecer transcurridas 3 semanas. En los casos de diseminación cutánea del herpes, existe un riesgo de un $5-10 \%$ de sufrir neumonitis, meningoencefalitis, hepatitis y otras complicaciones graves, aunque la mortalidad no es elevada. El cuadro más grave de presentación lo supone la diseminación visceral de la varicela, que se asocia a una mortalidad de hasta el $40-50 \%^{1,5}$. Se habla de probable diseminación visceral cuando se observa afectación pulmonar en la radiología de tórax o existen alteraciones analíticas de la función hepática o pancreática conjuntamente con la infección, sin poder descartarse otra causa, mientras que si se aísla el virus en el tejido afectado o se observan cambios histopatológicos compatibles se habla de diseminación docu- mentada ${ }^{1}$. En general, la diseminación visceral ocurre posteriormente a la aparición de la erupción cutánea, pero hay ocasiones en las que esta máxima no se cumple y la diseminación precede a la afectación cutánea. En estos casos, el primer síntoma de la infección suele ser un dolor abdominal inespecífico, localizado generalmente en epigastrio pudiéndose acompañar de náuseas y vómitos, así como de fiebre, diarrea o neumonitis. El aumento de las transaminasas, enzimas de colestasis y de la amilasa en sangre, puede estar presente desde el comienzo del cuadro y revela la afectación visceral de la infección que puede llegar a producir necrosis hemorrágica de varios órganos provocando una elevada mortalidad ${ }^{1,5}$. Los hallazgos endoscópicos pueden ser totalmente normales, o pueden aparecer lesiones granulares en la superficie de las vísceras afectadas, similares a las que se producen en la piel ${ }^{6}$.

En nuestro caso, la paciente comenzó con dolor abdominal intenso antes de producirse las lesiones cutáneas, apareciendo la alteración en la analítica hepática coincidiendo con las lesiones dérmicas. Estos datos indicaron la afectación visceral de la infección, que en nuestra paciente fue principalmente hepática, sin llegar a producirse afectación pancreática. Los hallazgos endoscópicos, en concordancia con lo publicado en la bibliografía, fueron normales, aunque dado que la gastroscopia se realizó durante las primeras 48 horas de ingreso, las lesiones podrían no haber aparecido todavía.

El tiempo medio entre el comienzo del dolor abdominal y la aparición de la erupción dérmica puede variar de 24 horas a 10-14 días ${ }^{1,5}$. Este hecho, junto con la inespecificidad de los síntomas y de los hallazgos de laboratorio, implica una mayor dificultad para el diagnóstico suponiendo, por ello, un retraso en la instauración del tratamiento y un aumento de la mortalidad que en algunos casos puede llegar hasta el $40-50 \%{ }^{1,5}$. En nuestra paciente, las lesiones aparecieron 48 horas tras el ingreso y, ante la sospecha de infección por VVZ, se inició tratamiento endovenoso con Aciclovir, logrando rápidamente controlar el dolor y la fiebre, comenzando poco después a normalizarse los valores analíticos. Este 
hecho hace que el diagnóstico de sospecha de infección diseminada por el VVZ ante un paciente inmunodeprimido con dolor abdominal, alteraciones en la analítica hepática y/o pancreática, aun en ausencia de lesiones cutáneas, dentro del primer año post-transplante, tome vital importancia para la instauración del tratamiento y evitar así complicaciones que pueden resultar fatales.

Por último, cabe destacar el beneficio del empleo en estos pacientes de profilaxis prolongada con antivirale $\mathbf{s}^{1,2,4} \mathrm{o}$ con las diferentes formas de inmunoprofilaxis que existen, como: la inmunización pasiva mediante la administración de inmunoglobulina específica de zoster (IGZ) o de varicela zoster (IGVZ), o el preparado de plasma inmune de zoster (PIZ), que deben ser administrados dentro de las primeras 96 horas post-exposición (en el caso del PIZ incluso más tarde); o la inmunización activa mediante la vacuna de virus vivos atenuados ${ }^{1,7}$. Actualmente se recomienda la vacunación en niños y adultos sanos, en niños con leucemia, en estadios iniciales de la infección por VIH, en pacientes con defectos humorales de la inmunidad y en personas que vayan a mantener un contacto cercano con pacientes inmunodeprimidos. En ocasiones, tras la vacunación, puede aparecer un rash maculopapular a partir del cual pueden transmitirse los virus atenuados de la propia vacuna. Por ello, la Academia Americana de Pediatría recomienda que en estos casos de rash se evite el contacto con pacientes inmunodeprimidos hasta la desaparición de la erupción ${ }^{8}$.

En el caso que nos ocupa, la paciente estuvo durante los primeros 6 meses posttrasplante con tratamiento profiláctico con Aciclovir a dosis de $400 \mathrm{mg} / 12$ horas, lo cual quizás retraso aunque pero no previno el posterior desarrollo de la infección.

\section{BIBLIOGRAFÍA}

1. Muñoz L, Balmaña J, Martino R, Sureda A RABELla N, BRUNET S. Dolor abdominal como forma de presentación de infección visceral por el virus varicela zoster en receptores de trasplante de progenitores hematopoyéticos. Med Clínica 1998; 111: 19-22.

2. Koc Y, Millar KB, Schenkein DP, GRIfFith J, AKHTAR M, DEsJARDIN J, SNYDMAN DR. Varicella zoster virus infections following allogeneic bone marrow transplatation: frecuency, risk factors and clinical outcome. Biol Blood Marrow Transplant 2000; 6: 44-49.

3. LOCKSLEY RM, FlOURnOY N, Sullivan KM, MEYERS JD. Infection with varicella zoster virus after marrow transplantation. J Infect Dis 1985; 152: 1172-1181.

4. Han CS, Millar W, HaAke R, Weisdorf D. Varicella zoster infection after bone marrow transplantation: risk factors and complications. Bone Marrow Transplantation 1994; 13: 277-283.

5. David DS, Tegtmeier BR, O' Donnell MR, PAZ IB, MCCARTY TM. Visceral varicella zoster after bone marrow transplantation report of a case series and review of the literature. Am J Gastroenterol 1998; 93: 810-813.

6. Uribarrena R, Garcila Bragado F, Jiménez C, Perez C, Rivero Puente A. Laparoscopic findings in two adults with chickenpox. Endoscopy 1988; 20: 83-85.

7. WHITLEY RJ. Infecciones por el virus varicelazoster. En: Braunwald E. y col, editores. Harrison. Principios de Medicina Interna. Madrid: Mcgraw-Hill (Interamericana), 2001: 1304-1306.

8. Scanlon-Kohlroser CA, Pang YF, Primack W, STOFF JS. Primary Varicella after transplation. Am J Kidney Dis 2002; 39: 1310-1312. 